\title{
Perforated Meckel's Diverticulum with Acute Appendicitis in an Infant
}

\author{
Tim Jumbi, Shahbal Swaleh, Francis Osawa
}

School of Medicine, University of Nairobi

Correspondence to: Dr. Tim Jumbi, PO Box 1059-00618, Ruaraka, Nairobi, Kenya; email: mwaitim@gmail.com

\section{Summary}

Meckel's diverticulum occurs in approximately $2 \%$ of the population and is symptomatic in $16 \%$ of cases. In children, the most common presentation is intestinal obstruction due to intussusception. The simultaneous occurrence of acute appendicitis and symptomatic Meckel's diverticulum is rare and when it occurs, it may be associated with non-specific symptoms that present a diagnostic challenge.
Keywords: Meckel's diverticulum, Acute appendicitis

Ann Afr Surg. 2020; 17(1): 42-44.

DOI: http://dx.doi.org/10.4314/aas.v17i11.11

\section{Conflicts of Interest: None}

Funding: None

(C) 2020 Author. This work is licensed under the Creative Commons Attribution 4.0 International License.

\section{Introduction}

In 1809 Meckel first reported Meckel's diverticulum (MD) by describing its embryological origin as a remnant of the omphalomesenteric duct (1). Meckel's diverticulum is the most common congenital malformation of the gastrointestinal tract with an incidence of between $2 \%$ and $4 \%$ (2). The occurrence of MD is mostly asymptomatic but is reported to be symptomatic in approximately $16 \%$ of cases (3). Symptomatic MD is defined by the presence of gastrointestinal bleeding, intestinal obstruction and peritonitis. The most common presentation in children is intestinal obstruction due to intussusception, with the diverticulum acting as a lead point (4). The simultaneous occurrence of appendicitis and symptomatic $\mathrm{MD}$ is rarely seen in adult and pediatric populations. This occurrence may present with non-specific symptoms, which can delay diagnosis and management in these patients. We report the case of a 7-month old admitted with the rare occurrence of a perforated Meckel's diverticulum and acute appendicitis. This case highlights the rarity and non-specific symptomatology of this occurrence with its diagnostic enigma that can delay intervention in the pediatric population.

\section{Case report}

We report a case of a 7-month old with a perforated MD and acute appendicitis, with the aim to highlight the symptomatology of this occurrence and its diagnostic enigma which can delay intervention in the pediatric population.
A 7-month-old male was admitted to the pediatric surgical unit at Kenyatta National Hospital with a 1-day history of abdominal pain, fever and vomiting. The abdominal pain was colicky and intermittent; the vomiting was non-bilious and postprandial. There was no history of constipation and the child was passing stool and flatus. He was clinically febrile with a temperature of $40^{\circ} \mathrm{C}$. He had a mildly distended abdomen which was mildly tender, no abdominal masses were palpated and bowel sounds were present. Mucoid soft faeces were noted on digital rectal examination with no rectal masses palpated. The WBC count was $11.2 \times 10^{9} / \mathrm{L}$ with a neutrophil count of $5.42 \times 10^{3} / \mu \mathrm{L}$. An initial abdominal $\mathrm{x}$-ray showed dilated bowel loops, predominantly small bowel with increased bowel wall attenuation (Fig. 1). An abdominal ultrasound was reported with no features of intussusception or free intraperitoneal fluid but was inconclusive of a diagnosis.
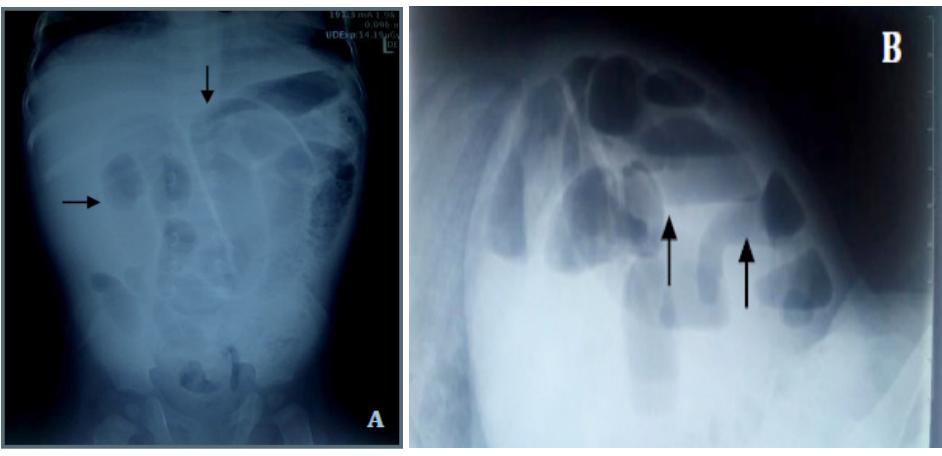

Figure 1. Preoperative plain radiographs. A) supine view showing dilated bowel loops with increased bowel wall attenuation; B) Dorsal decubitus view showing dilated bowel loops with multiple air fluid levels. 
We inserted a nasogastric tube for decompression and put the child on nil by mouth. In addition, we instituted intravenous fluids, antibiotics and antipyretics. After 6 hours of conservative management, the abdominal distension had subsided, the child had passed stool twice but still had fever and abdominal tenderness that had since worsened, being associated with guarding and rigidity. We performed an explorative laparotomy, as the child had developed clear signs of peritonitis. Intraoperatively, we found matted ileal and ceacal segments of bowel with fibrinous exudates that had concealed
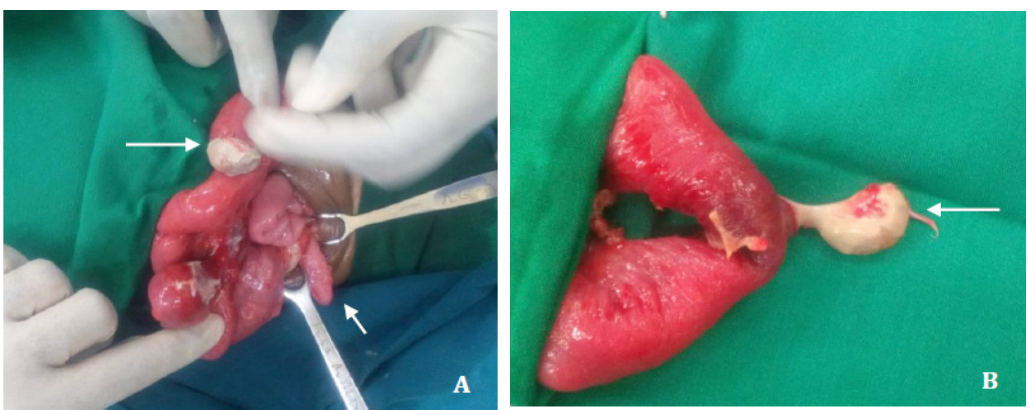

Figure 2. Intraoperative findings. A) The Meckel diverticulum (long white arrow) is seen covered with fibrinous exudate and a perforated tip. The diverticulum is close to the appendix (small white arrow) which is enlarged and inflamed. B) Meckel's diverticulum (long white arrow) is seen with a narrow neck and perforated tip. The adjacent bowel was resected with the diverticulum and end-to-end primary anastomosis done. a perforated Meckel's diverticulum and an inflamed appendix. The MD was $2 \mathrm{~cm}$ long with a small neck located $60 \mathrm{~cm}$ proximal to the ileocecal valve (Fig. 2).

We first removed the appendix then proceeded to do a segmental resection of the intestine with the diverticulum and end-to-end anastomosis of the adjacent bowel. The patient fully recovered and was discharged from the clinic. The resected appendix and diverticulum were sent for histology, which confirmed features of appendicitis with luminal suppuration and infiltration of polymorphs. The diverticulum had colonic mucosa, exhibiting features of diverticulitis with inflammation, ulceration and perforation.

\section{Discussion}

The diagnosis of MD presents a known challenge to the paediatric surgeon. Charles Mayo correctly stated that $\mathrm{MD}$ is frequently suspected, often looked for and seldom found (5). The preoperative diagnosis of symptomatic MD is difficult and is missed in most cases, especially in those that don't present with bleeding. The clinical presentations are diverse and may include abdominal pain, intestinal obstruction, diarrhea, lower gastrointestinal bleeding with jelly stool, and sometimes an abdominal palpable mass. The main clinical sign is gastrointestinal bleeding, reported in $25-50 \%$ of symptomatic patients with MD (6). In children, the most common presentation associated with MD is intestinal obstruction usually caused by intussusception, fibrous band volvulus, torsion of the diverticulum and Littre's internal hernia $(3,7-10)$. Peritonitis is also a common clinical presentation in children, which results from a perforated diverticulum or diverticulitis $(11,12)$. Our case presented with non-specific symptoms, suggestive of partial intestinal obstruction, which later progressed to peritonitis that was caused by the perforated $\mathrm{MD}$.

The association between $\mathrm{MD}$ and appendicitis is commonly established in the context of an MD found incidentally during appendectomy (13). However, the case described presents a rare simultaneous occurrence of a symptomatic MD in the presence of acute appendicitis. The clinical presentation of $\mathrm{MD}$ and that of appendicitis can be indistinguishable. First, both pathologies may present acutely with peri-umbilical pain, migratory pain and right iliac fossa tenderness. Second, both may have a progressive course with fever and leukocytosis. Finally, both may result in perforation, diffuse peritoneal contamination and septic shock $(14,15)$. Therefore, when a normal appearing appendix is found during a laparotomy for suspected appendicitis, an inflamed Meckel's diverticulum must be sought. The severity of appendicitis may determine the decision to resect an asymptomatic MD discovered during an appendectomy. This follows the recommendation that an MD detected incidentally should be left intact in the presence of complicated appendicitis with abscess, perforation or gangrene to reduce risk of postoperative complications (16). The decision to resect an incidentally detected MD also depends on other factors and is still a subject of controversy. A systematic review of this subject found that most authors favored removal of an asymptomatic diverticulum detected incidentally only if it occurred in males younger than 50 years, is longer than $2 \mathrm{~cm}$ and contains ectopic mucosa (2). This approach is linked to evidence that the lifetime risk of developing complications related to $\mathrm{MD}$ is low at $4-6 \%$ and consequently approximately 800 diverticular resections would need to be performed to prevent 1 death (17). It appears that resecting an MD detected incidentally is unnecessary as this may 
increase the perioperative morbidity risk in a patient whose lifetime risk of MD-associated complications is rather low. In patients with symptomatic MD, treatment is surgical resection by either simple diverticulectomy or segmental bowel resection and anastomosis, which are usually indicated when the diverticulum has a wide base or when it is associated with palpable ectopic tissue, intestinal ischemia and perforation (2). Recent literature suggests that macroscopic features of the diverticulum do not predict the presence of ectopic tissue and therefore a formal bowel resection is favored to simple diverticulectomy, which carries the risk of leaving behind hostile ectopic tissue usually at the base $(18,19)$. The most common ectopic mucosa is gastric and pancreatic with colonic, duodenal and biliary mucosa occurring less frequently (20). We opted for a formal bowel resection and anastomosis in our patient with a perforated $\mathrm{MD}$, which was an indication for such management coupled with the fear of leaving ectopic tissue, which was later confirmed by histopathology as colonic mucosa with diverticulitis.

\section{Conclusion}

Children with symptomatic MD usually present with intestinal obstruction and peritonitis but rarely present with bleeding, as seen in adults. The association between MD and appendicitis is commonly established in the context of an MD incidentally found during appendectomy. However, a symptomatic MD in the presence of acute appendicitis is a rare occurrence which may be associated with non-specific symptomatology that presents a diagnostic challenge, which can delay management especially in the pediatric population.

\section{References}

1. Meckel JF. Ueber die Divertikel am Darmkanal. Arch Physiol. 1809; 9:421-453.

2. Sagar J, Kumar V, Shah DK. Meckel's diverticulum: A systematic review. J R Soc Med. 2006; 99:501-5.

3. Park JJ, Wolff BG, Tollefson MK, et al. Meckel diverticulum: The Mayo Clinic experience with 1476 patients (19502002). Ann Surg. 2005; 241:529-33.S
4. t-Vil D, Brandt ML, Panic S, et al. Meckel's diverticulum in children: A 20-year review. J Pediatr Surg. 1991; 26:1289-92.

5. Mayo CW. Meckel's diverticulum. Pro Mayo Clin.1933; $8: 230$.

6. Pantongrag-Brown L, Levine MS, Buetow PC, et al. Meckel's enteroliths: Clinical, radiologic, and pathologic findings. Am J Roentgenol. 1996; 167:1447-50.

7. Ruscher KA, Fisher JN, Hughes CD, et al. National trends in the surgical management of Meckel's diverticulum. J Pediatr Surg. 2011; 46:893-6.

8. Ren B, Jia X, Meng X, et al. Intestinal obstruction due to axial torsion of a giant Meckel's diverticulum: A case report. Int J Colorectal Dis. 2015; 30:1133-4.

9. Deshmukh SN, Jadhav SP, Asole AG. Axial torsion and gangrene of a giant Meckel's diverticulum causing small bowel obstruction. Sri Lanka J Surg. 2015; 33:35-6.

10. Gerdes C, Akkermann O, Krüger V, et al. Incarceration of Meckel's diverticulum in a left paraduodenal Treitz' hernia. World J Clin Cases. 2015; 3:732-5.

11. Blevrakis E, Partalis N, Seremeti C, et al. Meckel's diverticulum in paediatric practice in Crete (Greece): A 10year review. Afr J Paediatr Surg. 2011; 8:279-82.

12. Rattan KN, Singh J, Dalal P, et al. Meckel's diverticulum in children: Our 12-year experience. Afr J Paediatr Surg. 2016; 13(4):170-4.

13. Smith EB. Acute appendicitis associated with Meckel's diverticulum. J Natl Med Assoc. 1960; 52(1):51-73.

14. Modi S, Kanapathy PS, DeClercq S. Perforated Meckel's diverticulum in an adult due to faecolith: A case report and review of literature. Int J Surg Case Rep. 2015; 15:143-5.

15. Senocak R, Ince M, Kaymak S, et al. Coexistence of acute appendicitis and perforated Meckel's diverticulitis: A rare presentation in older adults. J Clin Gastroenterol Treat. 2016; $2: 17$.

16. Ueberrueck T, Meyer L, Koch A, et al. The significance of Meckel's diverticulum in appendicitis-A retrospective analysis of 233 cases. World J. Surg. 2005; 29:455-8.

17. Zani A, Eaton S, Rees CM, et al. Incidentally detected Meckel diverticulum: To resect or not to resect? Ann Surg. 2008; 247:276-81.

18. Varcoe RL, Wong SW, Taylor CF, et al. Diverticulectomy is inadequate treatment for short Meckel's diverticulum with heterotopic mucosa. ANZ J Surg. 2004; 74:869-72.

19. Gezer HÖ, Temiz A, İnce E, et al. Meckel diverticulum in children: Evaluation of macroscopic appearance for guidance in subsequent surgery. J Pediatr Surg. 2016; 51(7):1177-80.

20. Lin XK, Huang XZ, Bao XZ, et al. Clinical characteristics of Meckel diverticulum in children: A retrospective review of a 15-year single-center experience. Medicine (Baltimore). 2017; 96(32):e 7760. 